\title{
Classroom Reinforcement Schedules and Their Effectiveness in Selected Kenyan Primary Schools
}

\author{
Mary Wangari Kinyanjui \\ Kiambu Institute of Science \& Technology, Kenya \\ Dr Peter J.O. Aloka \\ Jaramogi Oginga Odinga University of Science and Technology, Kenya \\ Email:jairopeteraloka@yahoo.com \\ Dr Sr Sabina K. Mutisya \\ Catholic University of Eastern Africa, Kenya \\ Dr Sr Florentina Ndunge Ndeke \\ Catholic University of Eastern Africa, Kenya \\ Dr Naphtal Michira Nyang'ara \\ Laikipia University, Kenya
}

Doi:10.5901/jesr.2015.v5n3p41

\section{Abstract}

The purpose of the study was to determine Classroom Reinforcement Schedules and Their Effectiveness in Selected Kenyan Primary Schools. The study employed a Mixed Methods design in which both quantitative and qualitative data were collected. The target population teachers and pupils from public primary schools. Data was collected by using questionnaires and interview schedules. Quantitative data was analyzed using inferential statistics while Qualitative data was analyzed by using the thematic and content analysis. The study reported on the use of praise, tangible items such as games and money were also moderately often used by the teachers. The participants also used both Continuous reinforcement and partial reinforcement schedules. The study recommends that, schools should enhance token economy programs which have long term effect. Moreover, teachers should deepen their knowledge on token economy programs for academic success.

Keywords: Classroom, Reinforcement, Strategies, effectiveness, Public, Primary Schools

\section{Introduction}

The concept of reinforcement in learning is not a twentieth century idea (Thungu, Wandera, Gachie \& Alumande, 2008). Reinforcement in learning was used by educationists of the ancient Greeks (Cotton, 2008). The students of the torah were provided with edible rewards back in the Twelfth Century. Other numerous accounts clarify that instructional reinforcement practices have been in use throughout history. As indicated by the modernized manuscript teaching of the ancient Greeks, parents and guardians of the time used immediate and delayed reinforcement. Tangible and edible types of rewards were given to children on order to acquire study habits and to like learning. Like in the olden times, instructional reinforcement in classroom teaching is still in use (Alberto \& Troutman, 2006). Instructional reinforcement is of great importance and interest to teachers since it provides clues to the reason for academic success or failure for learners in schools. In teaching, success occurs when desired behaviour is adequately reinforced (Slavin, 2009). The idea that learning can be stimulated and enhanced through the use of reinforcers dates back as far as the educational practices of the ancient Greeks (Bandura, 2008). Learning has always held a high place in many societies all over the world (Slavin, 2009). Edible rewards were provided to the students of the Torah as far back as the twelfth century (Bandura, 2009). Other numerous accounts clarify that instructional reinforcement practices have been in use throughout 
history. According to Thungu et al (2008) the medieval manuscript teaching of the ancient Greeks indicates that parents and guardians of the time used immediate and delayed reinforcements. Examples of reinforcements used at that time included tangible and edible types of reinforcement meant to induce children to acquire study habits and to love learning. This was, and still is because in the classroom learning, reinforcement is of interest to teachers and learners since it provides some clues to the reason for academic success or failure for the learners. In teaching, success occurs when desired behavior has been adequately reinforced (Bodenhausen, 2008).

Reinforcement strategies in classroom teaching are important factors that influence school learning (Marzano \& Pickering, 2007). Instructional reinforcement strategies are significant to a successful teacher's delivery of instruction. In particular, if teachers have high expectations of all their students, then positive reinforcement, encouragement, feedback and praise will come naturally and students will have an appreciation for learning and will be motivated to do well (Herrell, 2007). On the other hand, negative reinforcement is a psychological reinforcement by the removal of an unpleasant stimulus when a desired response occurs. Negative reinforcement uses the reward system. A person is rewarded fro desired behaviour by having something unpleasant removed. For example, a teacher may remove disapproval when a student studies. The result will be that the student studies more thus increasing the frequency of the study behaviour. Slavin (2009) emphasizes that the pleasure inherent while engaging in behaviour is the most important reinforcer that maintains behaviour. For example, some students have a habit of extending their prep for longer periods without any rewards. Other students like to read, draw, sing or play games for no reason other than the pleasure they draw from these activities. Reinforcers of this type are called intrinsic reinforcers and students can be described as being intrinsically motivated to engage in these activities. In other words, intrinsic reinforcers result to behaviours that students enjoy engaging in for their own sake without any other reward (Deci \& Ryan, 2005). Extrinsic reinforcers are controlled with intrinsic ones in that they are external rewards given to individuals in order to engage in behaviour without which they might not engage in. Research on intrinsic and extrinsic reinforcers provides evidences that reinforcing learners for certain behaviours they would have done anyway can undermine long-term intrinsic reinforcers (Deci \& Ryan, 2005). Rewards should be provided to learners based on standards performance. However, the extrinsic reinforcers such as grades or tangible rewards may influence students to learn just to get the rewards. This shows that the use of such types of reinforcers should only be used if they are effective and if they make a difference to the dynamics of students. Wong and Wong (2009) suggest that whole class reinforcers are the most effective in reinforcing classroom learning. However, teachers should explain to students that they do not merely receive reinforcers; rather, they should earn them.

The mean scores of Kenyan public primary schools in National Exams have declined in the last two years compared to those of private schools. Consequently, Sivi, (2007) recommends that a lot needs to be done to raise the general academic standards of public primary education in the district. The drop out rate of students is also quite high. The present study intends to investigate what goes on in classroom instruction and in particular the reinforcement strategies used in teaching since it is crucial in maintaining the learner's interest in learning and academic achievement. Even though there are many factors that affect academic performance, the current research deems reinforcement as a very important element in maintaining learners in the classroom and improving the academic performance in national exams, which is so low in public primary schools. In Kikuyu Division Kenya, performance in Kenya Certificate of Primary Education (KCPE) national examination by students from public schools is disappointing (MOE, 2010). For instance, in the year 2012, the first seventy schools in a ranking of 100 schools were from private schools. Only two public schools managed to be in the first 70 ranked schools which is $2 \%$ pass compared to $98 \%$ pass of private primary schools in the same district (MOE, 2012).

\section{Theoretical Framework and Literature Review}

\subsection{The Instrumental Learning theory}

The current study was guided by the Instrumental Learning theory propounded by B.F.Skinner. The theory is known as Instrumental or operant conditioning which is still commonly taught in psychology today. The theory states that an individual's behavior is a function of its consequences (Winkielman, 2005). The concept of reinforcement was Skinner's most important contribution to psychological sciences which he formalized in his principles of classical conditioning, which along with Watson's extreme environmentalists strongly influenced his own thinking. Skinner in his theory took a different direction. By applying his concepts on adjusting reinforcement or motivation through stimuli, institutions such as schools, prisons and mental institutions can gain a broader understanding of human behavior (Slavin,2009). The institutions will also comprehend why any organism behaves the way it does. Skinner did not dwell on a person's 
intentions or goals (Banaji, 2011), for him, it was an outward behavior and its environment that mattered. Reinforcement theory has been used in many areas of study among them animal training, raising children and teaching learners (Francis, 2007). Reinforcement theory focuses on observable behavior such as learning in the classroom. There are various primary approaches to reinforcement theory. They include positive reinforcement, negative reinforcement, extinction and punishment. One of the strengths of operant conditioning theory is that, it is very helpful in raising children, teaching them and shaping their behaviour. A child who has been rewarded for good behavior is likely to continue with that behavior. On the other hand, a child who has been punished for misbehavior is less likely to model that behavior again. However, the theory has a weakness in that if a child is reinforced all the time he displays good behavior, eventually gets exhausted or that form of reinforcement becomes extinct.

\subsection{Literature review}

Studies have been carried out on the reinforcement schedules employed in classroom teaching. In an experimental study of simple concurrent schedules of reinforcement by Becker, (2006) verbal performance was evaluated. The participants were university students recruited through flyers distributed in campus buildings in New York. Responding rates were used as dependent variables while preferred and non-preferred sound delivered to participants were the independent variables in a continuous schedule of reinforcement. Findings indicated that, in order to create a methodology for reinforcer indication, not only stimulus selection but other variables such as the schedules of reinforcement delivered, response cost and deprivation variables should be analyzed. Becker's study only investigated on the continuous reinforcement, unlike current study that studied whether there was a variety of a reinforcement schedule employed by the teachers during instruction. Rachel and Thomas, (2010) studied the effects of fixed time reinforcement on six students behaviour in the classroom where non-conformity to do classroom task was rampant. Data was quantitatively analyzed, and the findings indicated that partial reinforcement was more effective on the students' positive learning by behaviour. Rachel and Thomas (2010) study only adopted quantitative techniques but no qualitative data was obtained. The present study employed both qualitative and quantitative research design to fill this gap. Moreover, Moskwitz, (2011) studied comparison of variable ratio and fixed ratio schedules of Token reinforcement in Boston. The study used two students as participants for ratio schedules and two students aged six for fixed ratio schedules of 12 years for token economy. The findings were that, fixed ratio schedules seemed to be more effective than variable ratio schedules contrary to scientific proof that varied ratio is more effective. In addition, a lower response rate for varied condition for one individual was reported. Freidman, (2012) also conducted a research on comparison of reinforcement schedules for Boston students with different backgrounds, 23 from higher backgrounds and 27 from low economic status using purposive and random sampling. Reliable teacher reinforcement schedules indicated that pupil's socio-economic status, grade level interactions affected reinforcement schedules employed. Middle class level pupils significantly appreciated frequent non- verbal reinforcements than lower class pupils.

Previous studies have also been reported on effectiveness of reinforcement strategies. For example, Oyo, (2006) investigated the effectiveness of rewards system in Kenyan schools. The study focused on assessment of how rewards cause positive attitudes and therefore causes elevation of schools standards in academics. Instruments for data collection included questionnaires, both structured and semi-structured. The survey was 20 items of multiple choice questions of Likert Scales asked to state the frequency on what they prefer as rewards and types of rewards and reasons for their preferences. The findings revealed that most learners prefer simple items (pencils, erasers, stickers) as rewards and other classroom privileges such as computer time and homework pass. The study also investigated the effectiveness of the reward system in a primary school level unlike the reviewed study whose research was conducted in a secondary school level. Another study was carried out by Sammons, (2008) to investigate effective classroom practice by using mixed method research that is, quantitative and qualitative survey. The study investigated the effective classroom reinforcement practice in primary and secondary schools in England. The findings indicated that stimulating lesson climate, pro-active lesson management, well organized lesson with clear objectives, environmental teacher support, quality questions and feedback are effective classroom reinforcement strategies. In another study by Herbert, (2010) teachers' perception on the effectiveness of reward in an elementary level was surveyed in New York. The findings indicated that teachers used small items such as pens and classroom privileges which they reported were effective in motivating students. Dauncey, (2012) also investigated on effective classroom reinforcement strategies among first grade classroom level in central Pennsylvania. The study adopted qualitative approach, field observations and document analysis which were used to collect data. The findings indicated that tangible rewards are effective in reinforcing learners' desirable academic behaviour but they should be made contingent in the market or performance that each student can 
achieve with effort. Moreover, the findings also indicated that effective rewards should be specific to the individual or can be used for a whole class, where whole class would receive a reward based on the behaviour of the whole group.

From the review of literature review, most previous studies have been done based on the western context, and very scanty literature was available regarding Kenyan context. Moreover, most studies have adopted either a quantitative or qualitative approach, while the current study filled this gap by using both qualitative and quantitative approaches.

The study was guided by the following research questions:

- What reinforcement schedules are employed when reinforcing learners in the classroom when teaching, Kikuyu District, Kenya?

- Are the reinforcement strategies used by teachers in the classroom effective for teaching in Kikuyu District, Kenya?

\section{Research Methodology}

\subsection{Research design}

The study adopted a mixed methods paradigm, where both quantitative and qualitative data were collected. From the quantitative approach, the survey design was used to investigate populations by selecting samples to analyze and discover occurrences (Oso \& Owen, 2011). The descriptive survey design was used in the study since it is designed to collect information that describes, explores and help the researcher to investigate population based on sampling (Kothari, 2010). In addition, interviews were also used to collect qualitative data. Moreover, qualitative research allows the subjects being studied to give much 'richer' answers to questions put to them by the researcher and may give valuable insights which might have been missed by any other method.

\subsection{Study participants}

The target population for this study consisted of teachers in 30 public primary schools in Kikuyu District ( $\mathrm{N}=30)$. The study targets 100 teachers and 250 students from all the 30 public primary schools in Kikuyu District, Kiambu County of Kenya. The sample size was (30) public primary schools, 200 pupils who will be drawn from standards four to seven and 100 primary school teachers.

\subsection{Research instruments}

Questionnaires were used to collect quantitative data while interviews were used to collect qualitative data. The questionnaire for pupils and teachers were structured based on the main research questions namely; classroom reinforcement strategies, schedules of reinforcement and effective reinforcement strategies. The researcher used semistructured interviews which involved structured questions and use of open forms to probe more deeply in order to obtain additional information. Interview guides were administered to teachers randomly and purposely sampled. Moreover, observation guide was also used by the researcher to collect data about reinforcement strategies and the learning behavior reinforced. The research instruments were reviewed for validity by various groups of people who included the researcher's peers and supervisors at the Catholic University of Eastern Africa, Nairobi Kenya. These persons checked the instruments independently to ascertain whether they would solicit the right information as per expectations according to the research topic. Views on the content and structure were then incorporated in the final draft of the instruments. Trustworthiness of qualitative data was also ensured.

\subsection{Data collection procedures}

Permission to carry out the study was first obtained from The Catholic University of Eastern Africa, Nairobi Kenya and then two approved copies of research proposal were forwarded to the Ministry of Education Kenya for issuance of research permit. The researcher made prior arrangements with the class teachers for standard one to eight in the selected schools to assist in simple random sampling and in distribution of the questionnaires to the pupils. The purpose of the study was fully explained to participants in advance after which informed consent was obtained from them before interviews began. The researcher duly informed the respondents in the study that their participation was voluntary and that they were free to omit answers to any particular questions if they so chose. The researcher also protected their 
confidentiality and identity through use of numbers in line with recommended procedures that the participants should remain anonymous throughout the study. With the help of the head teacher and some teachers, the filled questionnaires were collected. Questionnaires completion took one week while interviews were done in secluded rooms and each lasted 30 minutes.

\subsection{Data analysis}

Data analysis is the process of bringing order and meaning to raw data (Kothari, 2011). The collected data was analyzed using both quantitative and qualitative data techniques. Quantitative data was analyzed using SPSS version 21, and the inferential statistics such as Chi-square and factor analysis were used. Qualitative data from the interview guides were analyzed using thematic framework. The quantitative and qualitative results obtained were both integrated.

\section{Findings and Discussion}

\subsection{Findings on Reinforcement schedules employed in classroom}

The study sought to find out the reinforcement schedules employed when reinforcing learners in the classroom. Both qualitative and quantitative results were obtained. The findings are presented in Table 1.

Table 1: Quantitative results on the selected reinforcers used in the classroom.

\begin{tabular}{lcccccc}
\hline Reinforcement & Very often & Often & Moderately often & Rarely & Very rarely & Never \\
\hline Praise & $74(75.5)$ & $18(18.4)$ & $4(4.1)$ & $1(1.0)$ & $1(1.0)$ & \\
Tangible items & $6(6.1)$ & $39(39.8)$ & $30(30.6)$ & $10(10.2)$ & $3(3.1)$ & $10(10.2)$ \\
Games, toys & $7(7.1)$ & $19(19.4)$ & $32(32.7)$ & $18(18.4)$ & $9(9.2)$ & $13(13.3)$ \\
Money \& points & $3(3.1)$ & $7(7.1)$ & $8(8.2)$ & $28(28.6)$ & $22(22.4)$ & $30(30.6)$ \\
\hline
\end{tabular}

From the quantitative results presented in Table 1, praise was used very often by $76 \%$ of the respondents. All the other strategies such as tangible items, games and money were moderately often used by the teachers. These findings have ranked praise as the most effective reinforcement strategies and it then explains why praise is the most often used reinforcement strategy in classroom teaching. In addition, the results also indicate that, money and points were the least often used reinforcement strategy in classroom instruction. The results also showed that $82 \%$ of the sampled teachers rarely used money and points as reinforcement. These findings however, contrast those raised from the pupils which indicated that money was a favourite reinforcement strategy among the learners.

The study investigated the reinforcement schedules employed by teachers in classroom teaching under the two main categories that is continuous and partial schedules of reinforcements.

\subsubsection{Continuous Reinforcement}

This refers to a teacher reinforcing the learner every time they display desired behaviour during classroom instruction. Continuous reinforcement generates enduring changes in learning behaviour. All the twenty respondents interviewed, reported to employing or using only one type of reinforcement schedule that is, continuous reinforcement. One male teacher emphasized on the excerpt that:

"From my observation, learners in public institutions especially the achievers need constant reinforcement every time they do well in class otherwise they will drop drastically in academic performance."

This finding emphasizes that teachers have to continuously reinforce learners in their academic endeavors. This is meant to prevent other factors such as poor learning conditions caused by harsh economic status from interfering with academic success. The excerpt contrasts the study by Moskwitz, (2011) which indicated that fixed ratio reinforcement schedule is the one known to be beneficial for both students and teachers. Continuous reinforcement according to scientific professionals leads to more rapid learning though it is not an efficient system of maintaining long term behaviour. It is not advisable to reward someone for every appropriate response. It is significant to eventually move from continuous to partial schedules of reinforcement. Once the task is well learnt under partial schedules of reinforcement, behaviour is more resistant to extinction. This is one of the weaknesses of Skinner's (1953) operant conditioning theory 
which states that, if an individual is reinforced all the time they display good behaviour, eventually that form of reinforcement becomes exhausted or leads to extinction. The implication is that teachers should employ both continuous and partial reinforcement for academic success.

\subsubsection{Partial reinforcement schedule}

Partial reinforcement or intermittent reinforcement refers to reinforcing learners only occasionally when desirable behaviour is displayed in teaching and learning. From all the teachers interviewed, only two admitted that they employ partial reinforcement schedule. Surprisingly, only two out of the twenty teachers interviewed reported that they use partial reinforcement. According to Becker (2006), in order to create a methodology for reinforcement indication, not only stimulus selected is important but also variables such as schedules of reinforcement employed and response cost. The idea of employing continuous reinforcement almost throughout contrasts Racho and Thomas (2010) whose findings indicated that partial reinforcement was more effective on students learning process as compared to continuous reinforcement schedule. The implication here is that teachers do not employ reinforcement schedules as per the theory but according to what they find practical in their set up. Therefore, there is need for implementation of reinforcement schedules according to the theoretical principles.

\subsection{Findings on Effectiveness of Reinforcement Strategies in the Classroom}

The researcher also sought to establish if reinforcement strategies used by teachers in the classroom were effective. Related items were posed to both pupils and teachers in their respective questionnaires.

\subsubsection{Pupils responses on Effectiveness of reinforcement strategies}

The study sought from the pupils how effective they found reinforcement to be in as far as their class work was concerned. Their responses were as shown in the Table 2.

Table 2: Pupil participants' responses on the effectiveness of reinforcement strategies

\begin{tabular}{lcc}
\hline Do you feel encouraged to do better in class work after the teacher praises you & \\
\hline Yes & 193 & 96 \\
No & 8 & 4 \\
Reason & 168 & 85 \\
I Feel Motivated \& encouraged to perform better & 25 & 13 \\
I want to be praised again & 4 & 2 \\
\hline
\end{tabular}

According to the findings presented in Table $2,96 \%$ of the sampled pupils indicated that they felt encouraged to do better in class work after the teacher praise them. The remaining $4 \%$ however, indicated that they did not feel encouraged at all. The findings indicate that "encouragement" was an important strategy not only in reinforcement but also in ensuring better academic work among learners. The findings are similar with Sammons (2008) who reported that, stimulating lesson climate, pro-active lesson management, well organized lesson with clear objectives, environmental teacher support, quality questions and feedback are effective classroom reinforcement strategies. The results therefore, provide evidence that reinforcement strategies can be incorporated by the teachers into their daily repertoire of classroom behavior management skills. This implies that reinforcement must be factored when teachers do their planning in teaching. Furthermore, the findings in Table 2 indicate that $85 \%$ of the sampled pupils felt motivated and encouraged to perform better while $2 \%$ of the pupils felt otherwise. This is in harmony with the other findings of this study already reported which have revealed that encouragement of learners is an effective strategy of classroom instruction. The findings in the table demonstrate a sharp contrast between pupils who felt motivated and those who did not feel any encouragement.

\subsubsection{Teachers' responses on effectiveness of Reinforcement Strategies}

In order to substantiate the findings from pupil participants, the researcher asked the teachers to respond to certain items 
in their questionnaire. The findings are as presented in the Table 3.

Table 3: Teacher participants' responses on effectiveness of Reinforcement Strategies

\begin{tabular}{lccccc}
\hline \multicolumn{5}{c}{ Very effective Effective } & Moderately effective Slightly effective Not effective \\
\hline Praise & $61(62.2)$ & $27(27.6)$ & $9(9.2)$ & $1(1.0)$ & \\
Tangible items & $56(57.1)$ & $32(32.7)$ & $6(6.1)$ & $2(2.0)$ & $2(2.0)$ \\
Games & $25(25.5)$ & $40(40.8)$ & $23(23.5)$ & $8(8.2)$ & $2(2.0)$ \\
Money \& points (tokens) & $21(21.4)$ & $41(41.8)$ & $20(20.4)$ & $7(7.1)$ & $9(9.1)$ \\
\hline
\end{tabular}

From the results presented in Table 3, 99\% of the sampled teachers felt that "praising" the learners during the lessons was an effective strategy in classroom reinforcement. The findings revealed that praise was the most effective of all the strategies. The effectiveness of praise as a reinforcement strategy in this study is in agreement with Maori (2008) who reported that, most teachers use social reinforcement such as verbal praise. This could be caused by the fact that verbal praise is almost instant hence the learner receives feedback on the spot after performing desirably. There were $96 \%$ of the sampled teachers in this study who perceived, "tangible items" to be very effective reinforcement strategy in the classroom. This means that tangible items were the second most effective reinforcement strategy. The findings confirm Maini (2011) who reported that, after teachers used reinforcement in the form of rewards and antecedent strategies, the majority of students improved in academic achievement. The results in Table 3 also show that $83 \%$ of the teachers who participated in this study found "money" and "tokens" as being an effective reinforcement strategy in classroom instruction. The results indicate that money can be a form of incentive for motivation among learners as the teachers have indicated. The researcher also sought to further investigate the relationship between reinforcement strategy and their effectiveness in the classroom. However, the earlier presented study findings indicated that money and tokens were rarely used by the teachers who participated in this study. Form the results in Table 3, praise, tangible items, games and tokens were all perceived as being effective by the teacher. This is in line with Moskwiz (2011) whose findings indicated that fixed schedules for token economy may be beneficial to teachers and students.

\subsubsection{The relationship between reinforcement strategy and their effectiveness in classroom instruction}

The teachers' and students' responses to items related to these two were cross tabulated and the results are presented in Table 4.

\subsubsection{Chi-square test results for Relationship between Reinforcement Strategy and their effectiveness}

A cross tabulation of students' responses on reinforcement strategies and their effectiveness in classroom instruction was carried out. The purpose of this chi-square test was to determine if a relationship exists between the two variables according to the students. The results are presented in Table 4.

Table 4: Cross tabulation of Reinforcement Strategies and their Effectiveness according to Pupils

\begin{tabular}{|c|c|c|c|c|c|c|}
\hline & & & $\begin{array}{l}\text { Do you feel encouraged to do b } \\
\text { praises you } 2 \\
\text { I Feel Motivated \& encouraged } \\
\text { to perform better }\end{array}$ & $\begin{array}{l}\text { etter class work } \\
\text { I want to be } \\
\text { praised again }\end{array}$ & $\begin{array}{l}\text { after the teacher } \\
\text { No } \\
\text { encouragement }\end{array}$ & Total \\
\hline you do well in class & Applauding & Count & 49 & 7 & 0 & 56 \\
\hline & & $\begin{array}{l}\text { Expected } \\
\text { Count }\end{array}$ & 46.6 & 7.8 & 1.7 & 56.0 \\
\hline & Through gifting & Count & 92 & 17 & 3 & 112 \\
\hline & & $\begin{array}{l}\text { Expected } \\
\text { Count }\end{array}$ & 93.1 & 15.5 & 3.3 & 112.0 \\
\hline & Encouraging me to work harder & Count & 27 & 4 & 3 & 34 \\
\hline & & $\begin{array}{l}\text { Expected } \\
\text { Count }\end{array}$ & 28.3 & 4.7 & 1.0 & 34.0 \\
\hline & Total & Count & 168 & 28 & 6 & 202 \\
\hline & & $\begin{array}{l}\text { Expected } \\
\text { Count }\end{array}$ & 168.0 & 28.0 & 6.0 & 202.0 \\
\hline
\end{tabular}


The findings in table 4 indicate that, there was an association between reinforcement strategy used by teachers and their effectiveness. This is demonstrated by the expected values and the count values which are not equal. Since the findings show that the expected count and the actual count are different, then, we conclude that there was a relationship.

A Chi Square was therefore connected to establish this relationship, and the results presented in Table 5.

Table 5: Chi-Square Tests Results on Effectiveness of Reinforcement strategies.

\begin{tabular}{lccc}
\hline & Value & Df & Asymp. Sig. (2-sided) \\
\hline Pearson Chi-Square & $6.138(\mathrm{a})$ & 4 & .189 \\
Likelihood Ratio & 6.436 & 4 & .169 \\
Linear-by-Linear Association & 2.817 & 1 & .093 \\
N of Valid Cases & 202 & & \\
\hline
\end{tabular}

a 4 cells $(44.4 \%)$ have expected count less than 5 . The minimum expected count is 1.01 .

From the statistical results in Table 5, the Chi-Square statistic, 6.138, is large when compared to the significance level, $p$ $<.189$ which is small. These findings show that it is very unlikely that reinforcement strategy used by a teacher and its effectiveness are independent of each other as variables in this study. Therefore, there is a relationship between a reinforcement strategy used by a teacher and its effectiveness. The study also sought teachers' responses reporting the effectiveness of reinforcement schedules.

\subsubsection{Teachers Responses on Effectiveness of Reinforcement Strategies}

In order to substantiate the findings from pupil participants, the researcher asked the teachers to respond to certain items in their questionnaire. The findings were as presented in the Table that 6.

Table 6: Teachers Responses on Effectiveness of Reinforcement Strategies

\begin{tabular}{lccccc}
\hline & Very effective & Effective & Moderately effective & Slightly effective & Not effective \\
\hline Praise & $61(62.2)$ & $27(27.6)$ & $9(9.2)$ & $1(1.0)$ & \\
Tangible items & $56(57.1)$ & $32(32.7)$ & $6(6.1)$ & $2(2.0)$ & $2(2.0)$ \\
Games & $25(25.5)$ & $40(40.8)$ & $23(23.5)$ & $8(8.2)$ & $2(2.0)$ \\
Money \& points (tokens) & $21(21.4)$ & $41(41.8)$ & $20(20.4)$ & $7(7.1)$ & $9(9.1)$ \\
\hline
\end{tabular}

From the results presented in Table 6, 99\% of the teacher participants felt that praising the learners during the lessons was an effective strategy in classroom reinforcement. The findings revealed that praise was the most effective of all the strategies. This finding is in agreement with Maori (2008) that most teachers use social reinforcement such as verbal praise. This could be caused by the fact that verbal praise is almost instant hence the learner receives feedback on the spot after performing desirably. The results also indicated that, $96 \%$ of the teacher participants perceived tangible items to be very effective reinforcement strategy in the classroom. This means that tangible items were the second most effective reinforcement strategy. The findings confirm Maini (2011) who reported that, after teachers used reinforcement in the form of rewards and antecedent strategies, the majority of students benefited in academic achievement. Moreover, $83 \%$ of the teachers' participants in this study found money and tokens as being an effective reinforcement strategy in classroom instruction. The results indicate that money can be a form of incentive for motivation among learners as the teachers have indicated. In general, praise, tangible items, games and tokens were all perceived as being effective by the teachers. However, these findings contradict those in an earlier section which indicated that money and tokens were rarely used by the teachers who participated in this study.

Although all types of reinforcers may be effective, their success depends on the reinforcement procedure being used. It is best practice to conduct reinforcer assessment, create preference lists such as reinforcer checklists, reinforcer menus, and interview the learner to find out what they would find reinforcing. To ascertain the relationship between reinforcement strategies and their effectiveness, Chi square test was carried out.

\subsubsection{Chi-square test results for Relationship between Reinforcement Strategy and their effectiveness}

The study sought to investigate relationship between reinforcement strategies and their effectiveness. Teachers' opinions 
were sought and the quantitative data analyzed. The results are presented in Table 7.

Table 7: Reinforcement strategies * Effectiveness Cross tabulation

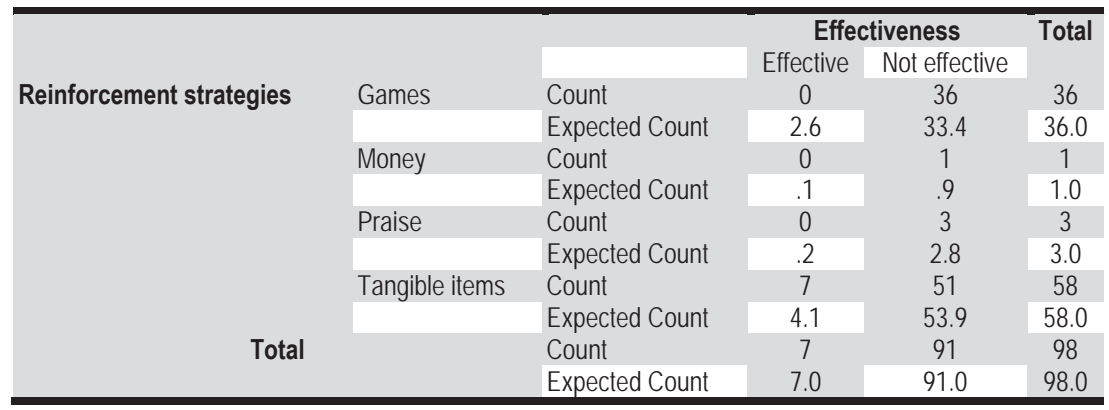

The results in Table 7 revealed an association between games and tangible items as reinforcement strategies and their effectiveness. This is evident from the differences in the expected count and the actual count values for these strategies as shown in Table 7. However, the expected count and the actual count for money and praise as reinforcement strategies suggest that there is no relationship as the two sets of values are almost equal. These findings show that these two sets of values are different from each other. If there was no relationship, both the expected count and the actual count values would be the same throughout.

To confirm the teachers' responses on effectiveness of reinforcement strategies, a Chi-Square test was carried out in Table 8

Table 8: Chi-Square Tests results on effectiveness on reinforcement strategies

\begin{tabular}{lccc}
\hline & Value & Df & Asymp. Sig. (2-sided) \\
Pearson Chi-Square & $5.199(\mathrm{a})$ & 3 & .158 \\
Likelihood Ratio & 7.712 & 3 & .052 \\
N of Valid Cases & 98 & & \\
\hline
\end{tabular}

A 6 cells $(75.0 \%)$ have expected count less than 5 . The minimum expected count is .07 .

The results in Table 8 show that, reinforcement strategy used and its effectiveness are independent of each other. This is evident from the large Chi-Square statistic, 5.199, against its small level of significance, $p<.158$. These findings show that it is very unlikely that reinforcement strategies used by a teacher and its effectiveness are independent of each other as variables in this study. Therefore, there is a relationship between a reinforcement strategy used by a teacher and its effectiveness. These findings are very similar to those raised from the chi-square test for teachers' responses on the same variables. This study therefore concludes that there is a relationship between the reinforcement strategy used by a teacher and the effectiveness of the strategy in classroom instruction.

Interviews were carried out to find out the effectiveness of various reinforcement strategies used in classroom teaching. The results were thematically analyzed. A majority of the teacher respondents interviewed affirmed that the reinforcement strategies they used in the classroom instruction worked or are effective. However, a few teachers reported that at times, they are not sure they have reinforced some individuals effectively. In some cases, teachers reported that they wished they would be sure what individual learners would wish to be used as reinforcers. A majority of respondents interviewed explained that they would prefer to reinforce learners with tangible items which they think were very effective. Some reported that they found simple items such as pencils, erasers among others quite effective. This is in line with Dancey (2012), who indicated that tangible rewards are more effective in reinforcing learners' desirable academic behaviour. However such tangible reinforcers should be made contingent to performance that learners achieve with effort. In addition, five of the respondents out of the twenty interviewed reported that they occasionally found group or whole class tangible rewards very effective. This is similar to Dancey (2012) who recommended that a whole class could receive a reward based on their group behaviour. Nevertheless, he cautions that such rewards are effective if they are specific to the individual group's characteristics and performance. According to Barnhill (2008), no learners' reward 
can be assumed to be a reinforcer for every individual under all conditions. This implies that reinforcing learners in a group is not likely to meet individual needs. Oyo (2006) investigated the effectiveness or reward system in Kenya and his findings revealed that most learners prefer simple items such as erasers, pencils, books and other classroom privileges such as computer time. Wafula, Wakhungu and Kafu (2011) in their study contrast the idea of tangible rewards by presupposing that rewards which are material in nature should not be frequently used. The implication here is that students who are reinforced with tangible rewards might perform learning tasks for the sake of rewards, rendering them ineffective.

Some respondents interviewed said that they often find activity reinforcement very effective. Some of the activity reinforcers they used included free time, play or games among others. It is a fact that young learners thrive a lot on play. Oyo 2006 in his study based in secondary school level indicated that privileges such as time with computers were effective reinforcers. However, Oyo's study was based in secondary school level where such equipment such as computers are available. So far, it was only in one public primary school out of the sample that possessed computers for learners. In that kind of a scenario, the implication is that activity reinforcers could only be used selectively and relevantly. Tokens are indirect reinforcers which can be exchanged with other preferred items. They include such items as money, points and stickers among others. Several participants who were interviewed said that tokens are effective reinforcers in classroom teaching despite the fact that they are unaffordable. Moskwitz (2011) reported that fixed ratio token is quite beneficial to both teachers and students alike. This implies that all effort should be put in place to ensure that tokens are availed to teachers so that they may use them for instructional reinforcement. One more experienced teacher in the profession claimed that all types of reinforcers can be effective. The following is an interview script of what he shared with the researcher:

"I am aware that generally, all types of reinforcement strategies can be effective. What really matters is whether the lesson climate is stimulating, and the classroom management is proactive. In addition, the lessons should be well organized with clear objectives and the environment made supportive by a friendly and warm teacher."

From the excerpt, it is clear that several types of reinforcement can be effective. However, even though all types of reinforcers may be effective, their success depends on the reinforcement procedure being used. It is best practice to conduct reinforcer assessment, create preference lists such as reinforcer checklists, reinforcer menus, and interview the learner to find out what they would find reinforcing. The qualitative findings are not very far from those in the quantitative data. The implication of the study is that effectiveness of reinforcement strategies may be dependent on other various factors.

\section{Concluding Remarks}

The study investigated classroom reinforcement schedules and their effectiveness in selected Kenyan primary schools. Reinforcement and its schedule play a key role in the condition of operant behavior and acquisition of learning. Where a continuous reinforcement schedule increases the response rate, the discontinuation of reinforcement may result in the extinction of that response or behaviour. A continuous reinforcement schedule, thus, yields the least resistance to extinction and the lowest response rate during learning. Learning of a response, therefore, occurs quickly if every correct response is rewarded, but it is forgotten easily when the reinforcement is stopped. If reinforcement is given after a varying number of correct responses or at varying intervals of time, the response is remarkably resistant to extinction. However the fixed interval reinforcement schedule (FIRS) are found to provide the lowest yield in terms of performance as the individual may soon learn to respond correctly only when the time or turn of reinforcement arrives. Similarly he may lose interest in getting reinforcement after a fixed interval or fixed number of correct responses. Weighing all these properly, Skinner suggests a $100 \%$ t schedule to begin with followed by a fixed interval or fixed ratio schedule to finally arrive at the variable reinforcement schedule for, better result in learning or training.

This study concludes that classroom reinforcement strategies vary in effectiveness and should therefore be carefully selected. Owing to this, a teacher is likely to embrace any of the reinforcement strategies at his disposal. However, caution must be taken to avoid strategies that may be way beyond the teacher's means. It is the responsibility of the teacher to carry out reinforcement assessment needed prior to using instructional reinforcement programs in order to ensure their success. The assessment will assist the teacher to heed to all learner's individual needs and interests. Emphasis should be laid on the use of reinforcement strategies that are likely to bring about intrinsic motivation to learners. In other words, extrinsic reinforcement should eventually graduate to intrinsic reinforcement. In addition, individual attention should be emphasized on in an attempt to cater for the needs and interests of the learners. This can 
only be achieved if the teacher-pupil ratio is improved by reducing the population in the present classroom in public primary schools. Further research study needs to be undertaken to include other classroom instruction tasks that have not been included in this study.

\section{References}

Alberto, P. \& Troutman, A. (2006). Applied Behaviour Analysis for Teachers. $7^{\text {th }}$ Edition Upper Saddle River, Prentice Hall Merriel. Banaji, M. (2011). Reinforcement Theory, Harvard gazette from http://www.newshavard.edu/gazette on 15th July, 2013.

Bandura, A. (2008). Organizational Application of Social Cognitive Theory. Australian Journal of Management, Volume 6, $275-302$.

Bandura, A. (2009). Human Agency in Social Cognitive Theory. American Psychologists Journal, Volume 15, 1175-1184.

Becker, H. J. (2006). Teachers Using Computers in Instruction. Paper presented at the meeting of the American Educational Research Association.

Bodenhausen, J. (2008). Does the Academic Background of Teachers Affect the Performance of their Students? Paper presented at the Annual Meeting of the American Educational Research Association, New Orleans, L.A. (ERIC Document Reproduction No. ED293836).

Cotton, C. (2008). Classroom Reinforcement. Herbert Welberg, University of Illinois, Chicago, USA.

Dauncy, L., (2012). Practical Reinforcement, Unpublished Masters thesis. University of Chichester, England.

Deci, E., \& Rayan, R. (2005). Extrinsic Rewards and Intrinsic Motivation in Education. Rochester University Press.

Francis, M. (2007). Life Skills Education. Retrieved on December 10, 2012 from http://www.changingminds.org/articles/articles/life_ skills education.htm.

Friedman, M. (2012). Comparison of Teacher Reinforcement Schedules for Students with Different Social Backgrounds. Journal of Educational Psychology, Volume 63 (3), 34-48.

Herell, F. (2007). Constructivist Teaching Strategies for Diverse Middle Level classrooms, Pearson Publisher., Boston U.S.A.

Kothari, C. R. (2011). Research Methodology. New Age International (P) Limited, New Delhi.

Maini, R. (2011). Teacher Training in a Proactive Approach to Classroom Behaviour Management. Unpublished PhD Thesis, University of Toronto, Canada.

Maori, T. (2008). Classroom Management Strategies. Unpublished Masters Thesis. University of Christ Church, New Zealand

Marzano, R., \& Pickering, D. (2007). The Case for and Against Homework. Educational Leadership. Alexandria, V. A.

Oso, W.Y and Onen D, (2011). A Handbook of Beginning Researchers. The Jomo Kenyatta Foundation. University of Nairobi, Kenya.

Oyo, O. (2012). Impact of Reward System in Kenyan Secondary Schools. Unpublished Masters thesis, Kenyatta University, Kenya.

Sammons, P. (2006). Effective Classroom Practice. University of Nottingham, United Kingdom.

Sivi, K. (2009). Social Issues Affecting Education. Kikuyu Strategic Plan website. Government Press, Nairobi.

Slavin, R. (2009). Educational Psychology: Theory and Practice (9th edition). Pearson International. Columbus, Ohio.

Thungu, J., Wandera, K., Gachie, L., \& Alumande, G. (2008). Mastering PTE Education. Oxford University Press: Nairobi.

Wafula, A., Wakhungu G., \& Kafu P. (2011). The State of Positive Reinforcement in Public Secondary Schools in Eldoret Municipality. International Journal of Current Research, Volume 3, 11, 38-70.

Winkielman, P. (2005). Cognitive Psychology. Guilford: New York, USA.

Wong, H. \& Wong, W. (2009). The First Days of School and How To Be an Effective Teacher. Harry K. Wong Publishers Inc. New Jersey. 
